\title{
Hospital costs and profitability related to the Patient Protection and Affordable Care Act
}

\author{
William Robert Pratt, Jerry D. Belloit \\ Department of Finance, Clarion University of Pennsylvania, United States
}

Correspondence: William Robert Pratt. Address: College of Business Administration, Clarion University of Pennsylvania, 840 Wood Street, Still Hall Office 325, Clarion, PA 16214, United States. E-mail: wpratt@clarion.edu

Received: September 10, 2013

Accepted: April 23, 2014

Online Published: May 20, 2014

DOI : $10.5430 /$ jha.v3n3p100

URL: http://dx.doi.org/10.5430/jha.v3n3p100

\begin{abstract}
On March 23, 2010, President Barack Obama signed into law the Patient Protection and Affordable Care Act (PPACA). This law was one of the most controversial and transforming pieces of legislation impacting health care delivery in recent history. The legislation was created in response to rising health care costs and the belief that, in part, cost shifting of indigent uninsured care to paying patients would reduce the overall costs of health care. The recent Supreme Court decision upholding the individual mandate portion of the law is expected to significantly reduce the number of uninsured. Using operational data from 212 hospitals in California, this study examines the anticipated impact on hospital costs, profitability, and some patient outcome benchmarks from the restructuring of health care delivery in the United States by the PPACA.
\end{abstract}

\section{Key words}

Patient Protection and Affordable Care Act, Obama care, Health finance, Hospital cost

\section{Introduction}

The Patient Protection and Affordable Care Act (PPACA) attempts a substantial restructuring of the health care delivery system in the United States. The legislation was created, in part, in order to stem the growth of federal spending on Medicare and Medicaid. According to the federal government Centers for Medicare and Medicaid, save more than \$575 billion over the next 10 years ${ }^{[1]}$.

“Net Medicare savings are estimated to total $\$ 575$ billion for fiscal years 2010-2019. Substantial savings are attributable to: ... productivity improvements ( $\$ 233$ billion); eliminate the Medicare Improvement Fund ( $\$ 27$ billion); reduce disproportionate share hospital (DSH) payments (\$50 billion); reduce Medicare Advantage payment benchmarks and permanently extend the authority to adjust for coding intensity ( $\$ 145$ billion); freeze the income thresholds ... ( $\$ 8$ billion); implement an Independent Payment Advisory Board together with strict Medicare expenditure growth rate targets (\$24 billion); and increase the high income payroll tax rate by 0.9 percentage point for individuals with incomes above $\$ 200,000$ and families above $\$ 250,000$ (\$63 billion)” ${ }^{[2]}$.

A long-standing problem with health care expense for hospital care is the expense of caring for the uninsured and underinsured. For decades these expenses have been born by those paying for hospital care through a process known as 
cost-shifting. Uninsured hospital patients are citizens who are unable to afford insurance, citizens who could afford insurance but choose to self-insure with inadequate asset reserves, or undocumented aliens lacking residency requirements to subscribe for coverage. Under-insured patients possess insurance, but lack an adequate level of coverage to pay for the care they consume. Under current law prior to full implementation of the PPACA, some cost-shifting is reduced by DSH payments. Another goal of the PPACA is the reduction of health care costs through the reduction of cost-shifting. By reducing the numbers of uninsured citizens, it is hoped that the PPACA will reduced the level of cost-shifting resulting in lower hospital costs and consequently lower insurance premiums and reduced Medicare and Medicaid expenses.

Another focus of the PPACA is the emphasis on quality of care. The law has several quality care funding initiatives. Hospitals will be rewarded or penalized based on their patient outcomes for specific conditions such as Acute Myocardial Infarction, pneumonia, and heart failure ${ }^{[3]}$. In addition, the PPACA attempts to control hospital costs through encouraging better care from the initial visit to the hospital by reducing the reimbursement rates for subsequent admissions for the same diagnosis ${ }^{[4]}$. However well intended, both of these programs can result in additional stress on a hospital's operating cash flow. This study examines the anticipated impact on hospital costs, profitability, and patient outcome benchmarks from the restructuring of health care delivery in the United States by the PPACA. As the PPACA calls for a reduction in Medicare reimbursements and an expansion of Medicaid, we examine how variables of interest (cash flows, mortality, and readmissions) differ across hospitals that provide a high proportion vis-à-vis hospitals that provide a low proportion of Medicare and Medicaid services to observe what occurs when the proportion of Medicaid funding increases and Medicare funding declines.

\section{Data}

The analysis employs financial, operating, and performance data from three data sets: the 2010 California Hospital Annual Financial Data (HAFD), Medicare Provider Analysis and Review (MPAR), and Hospital Compare. The HAFD files provide detailed financial and operating data at the hospital level of all licensed California hospitals and are accessible as public use data from the California Offices of Statewide Health Planning and Development (COSHPD). The MPAR and Hospital Compare data are provided by the Center for Medicare and Medicaid Services (CMS). From the MPAR data set we employ the Medicare case mix index (CMI) as a traditional method of accounting for heterogeneity of inpatient care between hospitals ${ }^{[5]}$. The Medicare CMI is used for adjusting the national average cost of treating patients relative to a specific hospital by dividing the national average cost by the CMI. Such that when making a comparison there is an inverse relationship between the adjusted national average cost of treating a patient within a Base Medicare Severity - Diagnosis Related Group (MS-DRG) and the CMI of a hospital in question. As example, if the average cost of treating a patient is $\$ 1,000$ and the hospital specific CMI is 0.5 , the adjusted national average cost of treating a patient is $\$ 2,000$. The adjustment results in an outcome where the national average increases (decreases) when a comparison hospital has a CMI below (above) one, such that the hospital in question has an average cost that is proportionally smaller (larger) to the national average once adjusted. The purpose of this adjustment is to account for the hospital specific patient volume and comorbidities treated for reimbursements, such that a higher CMI indicates a more complex patient group that ipso facto is more costly to treat relative to the national average.

The Hospital Compare database supplies measures of hospital mortality, readmission rates, and "Spending per hospital patient with Medicare". The latter measure indicates the proportional amount that Medicare spends treating patients in a specific hospital relative to other hospitals in the nation, where a value larger than one denotes a greater expense in treating patients and vice versa. To pair the COSHPD data with the data CMS, we hand matched hospitals as the hospital facility identifiers are dissimilar and hospital names vary - for instance the CMS database employs the name of Silver Lake Medical Center, where as COSHPD lists City of Angels Medical Center.

The initial combined data set included 442 hospitals. To attain a comparable and consistent data set we removed all critical access, rural, long-term care, Kaiser Permanente hospitals, psychiatric, and child centered hospitals. We exclude critical 
access and rural hospitals as reimbursement methods and amounts differ from standard hospitals - typically rural/critical access facilities receive higher reimbursements. Long-term care hospitals which we define as hospital providing $60 \%$ or more of self-reported long-term care were removed as these hospitals typically have the ability to control the patients they admit and therefore they have the ability to admit patients based on the patient's ability to pay and method of payment. The Kaiser Permanente healthcare organization reports the financial status of all of Kaiser California hospitals in a single consolidated report, thus financial information at the individual hospital level is unavailable for this analysis. Child centered hospitals, also known as “Children's hospitals”, were removed as these hospitals typically provide a much lower quantity of services for those with Medicare beyond the emergency setting, hence the services and reimbursement source are not consistent with our sample data. The end data set employed in this analysis is comprised of 212 California hospitals.

The summary statistics for our sample is presented in Table 1. The descriptives indicate a diverse set of payment mixes over the sample where payor types (Medicare, Medicaid [Medi-Cal], and Third Party) are not accepted by all hospitals or one payment type may constitute two-thirds of a hospital revenues. On average Medicare comprises one-third (33\%) of hospital payments and Medicaid (Medi-Cal) slightly less than one-fifth (19\%). Within the sample 10 percent of the hospitals are teaching facilities and 37 percent receive some amount of DSH funding. Hospital size varies greatly from 16 to 992 licensed beds. Patient days per hospital bed provides an indication of utilization as well as remaining capacity. The values are rather alarming, such that at the 75th percentile, or ipso facto, 25 percent of hospitals are at virtually at zero remaining capacity. This is inferred by observing at the 75th percentile utilization is at 356 patient days per bed, i.e., the bed is rarely unoccupied.

Table 1. Descriptive statistics

\begin{tabular}{llllllll}
\hline & Mean & St. Dev & P25 & Median & P75 & Min & Max \\
\hline Medicare Payments & 0.33 & 0.13 & 0.25 & 0.32 & 0.43 & 0.00 & 0.64 \\
Medicaid Payments & 0.19 & 0.14 & 0.08 & 0.17 & 0.27 & 0.00 & 0.67 \\
Third Party Payments & 0.05 & 0.08 & 0.01 & 0.03 & 0.05 & 0.00 & 0.68 \\
Teaching Hospitals & 0.10 & 0.31 & ------- & ------- & ------ & 0.00 & 1.00 \\
Disproportionate Share Hospital & 0.37 & 0.48 & ------ & ------- & ------- & 0.00 & 1.00 \\
Licensed Beds & 285.38 & 177.72 & 153.00 & 248.00 & 395.50 & 16.00 & 992.00 \\
Patient Days (Adjusted) & $87,743.89$ & $65,416.08$ & $41,298.50$ & $72,568.00$ & $116,498.5$ & $1,299.00$ & $397,140.0$ \\
Patient Days per Bed & 302.66 & 98.18 & 244.70 & 297.99 & 356.15 & 81.18 & 363.93 \\
Operating Cash Flow per Bed & $\$ 27,336$ & $\$ 138,693$ & $\$(10,007)$ & $\$ 35,190$ & $\$ 80,322$ & $\$(693,315)$ & $\$ 521,236$ \\
Medicare Case Mix Index & 1.23 & 0.27 & 1.06 & 1.21 & 1.34 & 0.68 & 3.08 \\
Spending per Hospital Patient & 1.03 & 0.11 & 0.97 & 1.01 & 1.07 & 0.76 & 1.49 \\
Mortality - Heart Attack (\%) & 15.13 & 1.47 & 14.10 & 15.10 & 16.00 & 10.50 & 18.80 \\
Mortality - Heart Failure (\%) & 10.98 & 1.69 & 9.85 & 10.95 & 11.80 & 7.10 & 15.90 \\
Mortality - Pneumonia (\%) & 11.55 & 2.10 & 9.90 & 11.40 & 12.90 & 6.80 & 18.10 \\
Readmission - Heart Attack (\%) & 19.48 & 1.46 & 18.50 & 19.50 & 20.30 & 15.40 & 23.80 \\
Readmission - Heart Failure (\%) & 24.54 & 1.65 & 23.40 & 24.50 & 25.70 & 20.00 & 28.30 \\
Readmission - Pneumonia (\%) & 18.30 & 1.39 & 17.3 & 18.1 & 19.1 & 15.3 & 22 \\
Bad Debt (\$M) & $\$ 17.38$ & $\$ 18.22$ & $\$ 6.54$ & $\$ 12.71$ & $\$ 23.18$ & $\$-0-$ & $\$ 172.01$ \\
\hline
\end{tabular}

\section{Statistical analysis}

The PPACA calls for a large reduction in Medicare and DSH funding and an increase in Medicaid funding. To assess the impact of a decrease Medicare funding and an increase in Medicaid funding we form three groups of quintiles: the proportion of Medicare patient days relative to total patient days (adjusted), proportion of Medicaid patient days relative to total patient days (adjusted), and the operating cash flow per licensed bed - we normalize our data by the number of 
licensed hospital beds to draw comparable values. The reader may want to refer to Table 2 for an overview of how variables were calculated. After forming the quintiles we employ a comparative means analysis to assess variation across the quintile groups $(0-20 \%, 20 \%-40 \%, 40 \%-60 \%, 60 \%-80 \%, 80 \%-100 \%)$ relative to characteristics of interest (cash flow, patient heterogeneity[CMI], mortality, readmissions); we also employ a sensitivity analysis to examine how reductions in cash flow will affect the hospital sample. With respect to the comparative means analysis, Kruskal-Wallis tests are used to denote if the differences are statistically significant or not. The sensitivity analysis focuses on reductions in Medicare reimbursements and DSH funding. The estimates were attained using Stata 13.0.

Table 2. Calculation methods of the variables

\begin{tabular}{ll}
\hline Item & Calculation Method \\
\hline Operating Cash Flow & $=$ EBIT + Depreciation - Tax \\
$\%$ Medicare Patient Days & $=$ Medicare patient days / total patient days (adjusted) \\
$\%$ Medicaid Patient Days & $=$ Medicaid patient days / total patient days (adjusted) \\
Case Mix Index & $=$ Sum of the MS-DRG weights / total number of discharges \\
\hline
\end{tabular}

\section{Results}

In Table 3, quintiles of Medicare days per hospital bed are presented. The data indicate that operating cash flow (OCF) per bed is inversely related to death rates for heart attack, heart failure, and pneumonia patient, with the most pronounced inverse relationship is between OCF and heart attack - refer to Figure 1. However, it is important to recognize that factors such as case mix index and spending per patient influence each hospital's operating cash flow, such that without further investigation it would be imprudent to speculate that OCF drives heart attack mortality rates or visa versa. We also observe an increase in the complexity of patients treated in hospitals that provide a greater proportion of services to Medicare patients as measure via the Medicare Case Mix Index, possibly indicating an increase in skill/ability in treating patients that carryover in managing treatment cost. With respect to readmission rates a statistical difference is not observed.

Table 3. Quintiles of Medicare patient days

\begin{tabular}{|c|c|c|c|c|c|c|c|c|c|c|}
\hline & & $\begin{array}{l}\text { OCF per } \\
\text { Bed }\end{array}$ & $\begin{array}{l}\text { Case } \\
\text { Mix } \\
\text { Index }\end{array}$ & $\begin{array}{l}\text { Spending } \\
\text { Per Hospital } \\
\text { Patient }\end{array}$ & $\begin{array}{l}\text { Mortality } \\
\text {-Heart } \\
\text { Attack }\end{array}$ & $\begin{array}{l}\text { Mortality } \\
\text {-Heart } \\
\text { Failure }\end{array}$ & $\begin{array}{l}\text { Mortality } \\
\text {-Pneumo } \\
\text { nia }\end{array}$ & $\begin{array}{l}\text { Readmission } \\
\text {-Heart } \\
\text { Attack }\end{array}$ & $\begin{array}{l}\text { Readmissi } \\
\text { on -Heart } \\
\text { Failure }\end{array}$ & $\begin{array}{l}\text { Readmis } \\
\text { sion-Pne } \\
\text { umonia }\end{array}$ \\
\hline \multirow[t]{3}{*}{$\begin{array}{l}\text { Highest } \\
\text { proportion }\end{array}$} & $80 \%-100 \%$ & 35452.35 & 1.33 & 1.05 & $14.57 \%$ & $10.73 \%$ & $10.91 \%$ & $19.44 \%$ & $24.42 \%$ & $18.03 \%$ \\
\hline & $60 \%-80 \%$ & 10129.82 & 1.30 & 1.02 & $15.30 \%$ & $11.03 \%$ & $11.33 \%$ & $19.56 \%$ & $24.32 \%$ & $18.19 \%$ \\
\hline & $40 \%-60 \%$ & 88607.15 & 1.23 & 1.01 & $14.90 \%$ & $10.97 \%$ & $11.87 \%$ & $19.31 \%$ & $24.46 \%$ & $18.46 \%$ \\
\hline $\begin{array}{l}\text { Lowest } \\
\text { proportion }\end{array}$ & $0-20 \%$ & -43245.06 & 1.12 & 1.02 & $15.52 \%$ & $11.28 \%$ & $12.19 \%$ & $19.40 \%$ & $24.60 \%$ & $18.41 \%$ \\
\hline $\begin{array}{l}\text { Kruskal- } \\
\text { Wallis Prob. }\end{array}$ & & .0001 & .0001 & .9225 & .0163 & .5079 & .0499 & .8181 & .6148 & .2538 \\
\hline
\end{tabular}

Table 4. Quintiles of Medicaid patient days

\begin{tabular}{|c|c|c|c|c|c|c|c|c|c|c|}
\hline & & $\begin{array}{l}\text { OCF per } \\
\text { Bed }\end{array}$ & $\begin{array}{l}\text { Case } \\
\text { Mix } \\
\text { Index }\end{array}$ & $\begin{array}{l}\text { Spending } \\
\text { Per } \\
\text { Hospital } \\
\text { Patient }\end{array}$ & $\begin{array}{l}\text { Mortality } \\
\text {-Heart } \\
\text { Attack }\end{array}$ & $\begin{array}{l}\text { Mortality } \\
\text {-Heart } \\
\text { Failure }\end{array}$ & $\begin{array}{l}\text { Mortality } \\
\text {-Pneumo } \\
\text { nia }\end{array}$ & $\begin{array}{l}\text { Readmission } \\
\text {-Heart } \\
\text { Attack }\end{array}$ & $\begin{array}{l}\text { Readmission } \\
\text {-Heart } \\
\text { Failure }\end{array}$ & $\begin{array}{l}\text { Readmiss } \\
\text { ion-Pneu } \\
\text { monia }\end{array}$ \\
\hline \multirow[t]{4}{*}{$\begin{array}{l}\text { Highest } \\
\text { proportion }\end{array}$} & $80 \%-100 \%$ & -71987.77 & 1.05 & 1.09 & $15.39 \%$ & $10.64 \%$ & $11.67 \%$ & $19.39 \%$ & $25.07 \%$ & $18.52 \%$ \\
\hline & $60 \%-80 \%$ & 24474.19 & 1.19 & 1.03 & $15.01 \%$ & $10.98 \%$ & $11.69 \%$ & $19.86 \%$ & $24.97 \%$ & $18.65 \%$ \\
\hline & $40 \%-60 \%$ & 52061.03 & 1.29 & 1.02 & $15.22 \%$ & $11.10 \%$ & $11.81 \%$ & $19.40 \%$ & $24.22 \%$ & $18.23 \%$ \\
\hline & $20 \%-40 \%$ & 49748.03 & 1.29 & 0.99 & $14.95 \%$ & $11.04 \%$ & $11.52 \%$ & $19.46 \%$ & $24.36 \%$ & $18.27 \%$ \\
\hline $\begin{array}{l}\text { Lowest } \\
\text { proportion }\end{array}$ & $0-20 \%$ & 80529.68 & 1.35 & 1.01 & $15.16 \%$ & $11.09 \%$ & $11.08 \%$ & $19.26 \%$ & $24.09 \%$ & $17.85 \%$ \\
\hline $\begin{array}{l}\text { Kruskal- } \\
\text { Wallis Prob. }\end{array}$ & & .0001 & .0001 & .0118 & .7699 & .7789 & .6312 & .1801 & .0245 & .0909 \\
\hline
\end{tabular}


Table 4 reveals that the proportion of Medicaid (Medi-Cal) is inversely related to proportion of Medicare, as observed in Table 3. Specifically, as the proportion of Medicaid patients increases the OCF per bed falls, spending per patient increases, and death rates increase, as well there is a small but insignificant uptick in readmissions. This observation would suggest a reduction in the effectiveness of health services when the proportion of Medicaid increases.
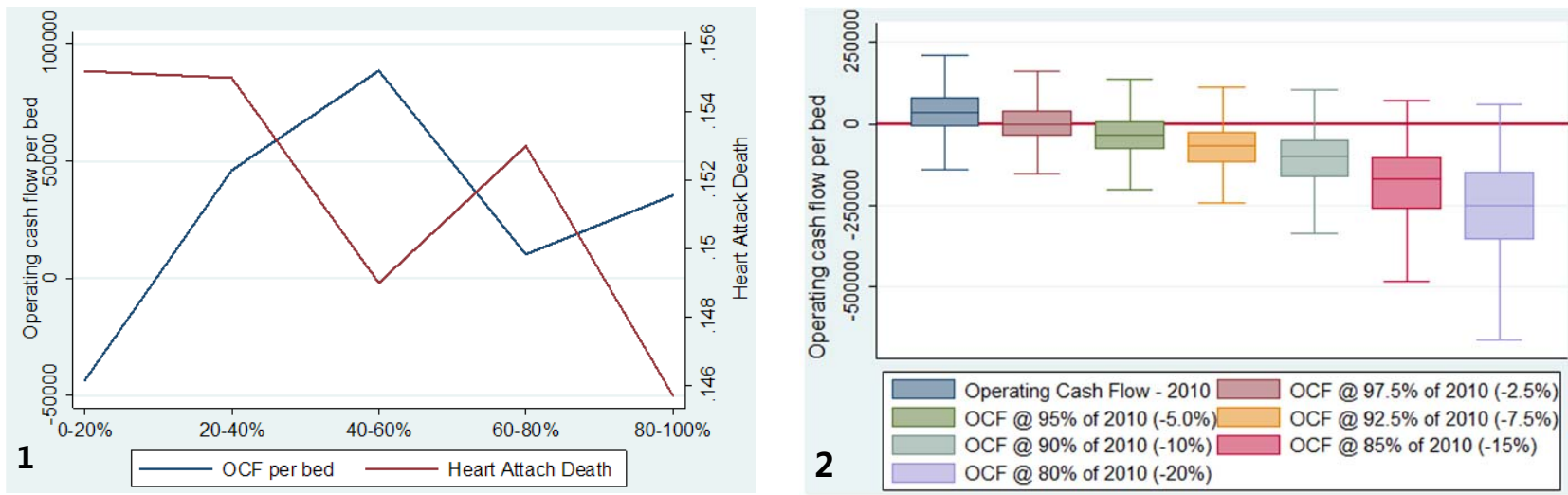

Figure 1. Operating cash flow relative to heart attack

Figure 2. Operating cash flow relative to Medicare reimbursements

Figure 3. Proportion of hospitals with negative OCF under Medicare reductions

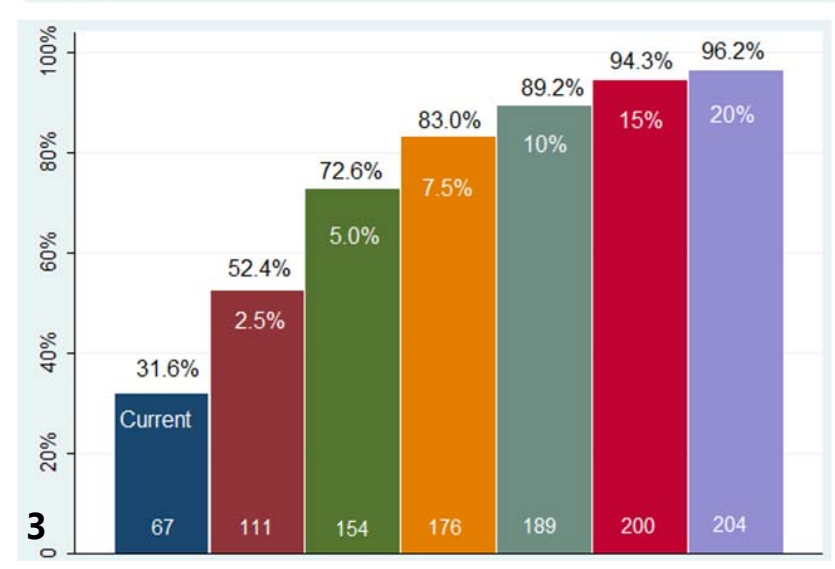

Table 5. Health outcomes by quintiles of OCF per bed comparing hospital receiving DSH relative to Non-DSH*

\begin{tabular}{llllllll}
\hline & & $\begin{array}{l}\text { Mortality- } \\
\text { Heart Attack }\end{array}$ & $\begin{array}{l}\text { Mortality- } \\
\text { Heart Failure }\end{array}$ & $\begin{array}{l}\text { Mortality- } \\
\text { Pneumonia }\end{array}$ & $\begin{array}{l}\text { Readmission- } \\
\text { Heart Attack }\end{array}$ & $\begin{array}{l}\text { Readmission- } \\
\text { Heart Failure }\end{array}$ & $\begin{array}{l}\text { Readmission- } \\
\text { Pneumonia }\end{array}$ \\
\hline $\begin{array}{l}\text { Lowest OCF } \\
\text { per bed }\end{array}$ & $0-20 \%$ & $5.40 \%$ & $4.92 \%$ & $7.98 \%$ & $2.13 \%$ & $5.17 \%$ & $3.31 \%$ \\
& $20 \%-40 \%$ & $1.03 \%$ & $-3.80 \%$ & $2.53 \%$ & $-3.83 \%$ & $-0.03 \%$ & $-1.09 \%$ \\
& $40 \%-60 \%$ & $2.46 \%$ & $-5.42 \%$ & $-3.48 \%$ & $0.97 \%$ & $-1.29 \%$ & $4.58 \%$ \\
& $60 \%-80 \%$ & $-2.55 \%$ & $-5.12 \%$ & $-5.55 \%$ & $6.75 \%$ & $5.46 \%$ & $6.03 \%$ \\
Kruskal- & $80 \%-100 \%$ & $-0.38 \%$ & $-10.45 \%$ & $1.40 \%$ & $5.11 \%$ & $4.61 \%$ & $3.95 \%$ \\
Wallis Prob. & & .0001 & .0001 & .0001 & .0001 & .0001 & \\
\hline
\end{tabular}

* DSH - Disproportionate Share Hospitals

Table 5 presents health outcomes observed in hospitals receiving DSH funding in relation to hospitals that do not receive DSH funding. The results show that at the lowest OCF per bed quintile, there is a notable increase in the death rates across all three categories. However, when OCF increases, institutions receiving DSH funds have improved health outcomes relative to non-DSH receiving hospitals. This implies that if DSH and other sources of funding are greatly decreased, we should expect health outcomes to move towards the lowest OCF per bed quintile. We also consider the impact of reduced Medicare reimbursements as outlined in the PPACA - calling for a 10 percent reduction in reimbursements. Figure 2 charts OCF per bed with reductions in Medicare beginning with a 2.5 percent reduction up to a 20 percent reduction. 
Figure 3 aids Figure 2 by presenting the proportion of hospitals incurring negative OCF with reductions in Medicare. At the reduction level called for by the PPACA (10\%), 89.2 percent of the hospitals within the sample will experience negative OCF - without consideration of other planned reductions in reimbursements.

\section{I mplications for the future and unintended consequences}

Since 1990, 27\% of the emergency rooms have closed ${ }^{[6]}$. While this trend obviously began well before the PPACA, it is interesting to note that the study suggests that hospitals with high Medicare and Medicaid usage increase the likelihood of closure ${ }^{[7]}$. Since the PPACA dramatically expands the number of persons effectively covered by Medicaid, Table 4 suggests a drop in operational cash flow. As suggested by Hsia, this further increases the likelihood of emergency room closures. In addition, a possible response for a hospital attempting to maintain profitability under the reduced reimbursement for Medicare, Medicaid, and the public insurance exchange is for the hospitals to elect to eliminate emergency care. Emergency care is often a "loss-leader" for hospitals under current reimbursement programs. Under the PPACA, however, admissions for those under Medicare, Medicaid, and the public insurance exchange are likely to see a reduction in revenue from the government. By eliminating emergency care, there will be less admission of indigent care and government controlled reimbursements. To the extent that private insurance companies do not follow the public insurance exchange reimbursement rates, hospitals can be less concerned with the rates charged to paying patients and readmissions. This poses serious questions about access to emergency care, especially if non-mandated rural hospitals follow the trend of elimination of emergency care.

A significant concern over PPACA is the fear that there will actually be significantly less access to health care for those covered by Medicare, Medicaid, and the government insurance exchange. This lack of access is expected to result from fewer hospitals that will accept Medicare, Medicaid, and government insurance exchange patients since there will likely be fewer emergency rooms. At the same time, the PPACA is expected to reduce the number of uninsured by 44.5 percent and subsequently increase Medicaid enrollment by 27.4 percent ${ }^{[8]}$. These numbers will likely result in a significant increase in the demand for medical services and will likely stress the capacity of the health care delivery system. In addition, there will likely be fewer doctors. Various studies have suggested that many doctors would discontinue their practice of medicine under the PPACA ${ }^{[9,10]}$.

This combination of fewer hospitals and fewer doctors and increased demand for care will likely lead to significant health care shortages. Even though the PPACA contains several provisions to improve the quality of patient care, the likely shortage of care relative to the demand for care may actually result in worse patient outcomes. Ironically, even though there will be millions more people covered by at least minimum insurance, there may actually be less care available than under the system that currently is in operation.

It is reasonable that under the PPACA, hospital will be under significant pressure to reduce costs. One of the more easy ways for a hospital to reduce costs is to reduce the number of patient days necessary for the patient to recover. The challenge for the hospitals is to reduce patient days without readmission. The PPACA penalizes hospitals if the patient is readmitted for the same illness within a short time after the patient was first released. The readmission penalty might tend to extend the number of patient days for the illness. Breakthroughs in technology over the past few years have made home monitoring of vitals a practical solution that may be more likely to be expanded ${ }^{[11]}$. The PPACA does encourage innovation in health care delivery. This kind of innovation could help significantly, especially if hospitals are stressed by overcrowding from the expected increase in utilization.

It is clear that the PPACA will have some far reaching impacts on health care delivery in the United States. Some of these impacts are unlikely to have the result intended by the legislation. These unintended consequences will need to be addressed. 


\section{Author's statement}

This paper clearly expresses the views of the authors as there are no competing interests. For enquires on the views of this document please contact the authors.

\section{References}

[1] CMS Office of the Actuary. Affordable Care Act Update: Implementing Medicare Cost Savings. Centers for Medicare and Medicaid Services. 2010.

[2] Foster, Richard S. Estimated Financial Effects of the "Patient Protection and Affordable Care Act" as Amended. Centers for Medicare and Medicaid Services. April 22, 2010. Available from: http://www.cms.gov/ActuarialStudies/Downloads/PPACA_2010-04-22.pdf

[3] Public Law 111-148, SEC. 3001. Hospital Value-Based Purchasing Program.

[4] Public Law 111-148, SEC. 3025. Hospital Readmissions Reduction Program.

[5] Pratt, W.R. What Does Free Cash Flow Tell Us About Hospital Efficiency? A Stochastic Frontier Analysis of Cost Inefficiency in California Hospitals. Journal of Health Care Finance. 2010; 37(1): 35-44. PMid: 20973372.

[6] Hsia, Kellerman, Shen. Factors Associated With Closures of Emergency Departments in the United States. JAMA. May 18, 2011; 305(19). http://dx.doi.org/10.1001/jama.2011.620

[7] See also Hsia, et al. System-Level Health Disparities in California Emergency Departments: Minorities and Medicaid Patients Are at Higher Risk of Losing Their Emergency Departments. Annals of Emergency Medicine. 2011; 59(5).

[8] Holahan, John, Headen, Irene. Medicare Coverage and Spending Reform: National and State-by-State Results for Adults at or Below 133\% FPL. Urban Institute. May 2010.

[9] Jones, Terry. 45\% Of Doctors Would Consider Quitting If Congress Passes Health Care Overhaul. Investor’s Business Daily. 9/15/2009. Available from:

http://news.investors.com/091509-506199-45-of-doctors-would-consider-quitting-if-congress-passes-health-care-overhaul.aspx\#i xzz29yydNypZ

[10] Morgan, Rick. Poll: 83\% of doctors have considered quitting because of Obamacare. American Thinker. October 17, 2012. Available from: http://www.americanthinker.com/blog/2012/07/poll_83_of_doctors_have_considered_quitting_because_of_obamacare.html\#ixz z29z4B2HAc

[11] The State of Texas put a law into effect on 9/1/2011 that allows home monitoring of some Medicaid patients using telemedicine medical services. Available from: http://www.capitol.state.tx.us/BillLookup/History.aspx?LegSess=82R\&Bill=SB293 